\title{
A new species of Maratus (Araneae: Salticidae) from southwestern Australia
}

\author{
Julianne M. Waldock \\ Department of Terrestrial Zoology, Western Australian Museum, Locked Bag 49, \\ Welshpool D.C. Westem Australia 6986, Australia.
}

\begin{abstract}
A new species of the salticid genus Maratus, Maratus limmeri is described from southwestem Western Australia.
\end{abstract}

\section{INTRODUCTION}

The Australian endemic spider genus Maratus Karsch 1878 was first described from "Austral. sept." based upon M. amabilis and M. amocmus (now recognised as a synonym of M. volans (O.P.Cambridge)) (see Żabka 1987). It was subsequently synonymised with Saitis Simon 1876 (Simon 1901a, 1901b), and revalidated by Żabka (1987) who provided morphological features that could be used to separate these two genera: males of Maratus species have a scute over the entire dorsal abdomen which has extendable side-flaps and is covered with special coloured hairs which given the abdomen a silk-like lustre that can vary in colour according to the angle of view. These modifications and the colours and patterns of the coloured hairs are species specific. Males also have the third legs longer than the others and these legs have a thick brush of hairs on the tibia and metatarsi (and other leg segments and legs depending on the species) whilst the tarsi of these legs have thick white hairs on the dorsal surface.

Female Maratus have body patterning in varying amounts of speckling and patching in creams, tans, browns, greys and blacks that are species specific but they lack any of the special attributes of the males and must be distinguished from related genera by genitalic differences. The main distinguishing feature in female Maratus genitalia is that the spermathecae are wider than the fossae. The genus currently contains six named species (Platnick 2008), all from Australia: M. amabilis Karsch 1878; M. mungaich Waldock 1995; M. prionis (Dunn 1947); M. minboril (Roewer 1951), M. vespertilio (Simon 1901a) and M. volme (O.P.-Cambridge 1874). During an on-going revision of Maratus, about 15 new species have been recognised (Waldock, unpublished data), greatly expanding the diversity and extent of the group. Many of these species are highly restricted in distribution, including a new species from Two Peoples Bay Nature Reserve in southwestern
Australia. To further document the diversity of Maratus in Australia, I hereby describe this new species.

All of the material examined for this study is lodged in the Western Australian Museum, Perth (WAM). The female genitalia were examined by dissecting the epigynum from the abdomen and clearing it in $10^{\%} \%$ lactic acid at room temperature for a day. The epigynum was mounted in glycerol and drawn with a camera lucida on an Olympus BH-2 compound microscope. Other drawings were made using a graticule fitted to a Leica MS 5 dissecting microscope.

\section{SYSTEMATICS}

\section{Family Salticidae Blackwall 1841}

\section{Genus Maratus Karsch 1878}

Maratus Karsch 1878: 27; Żabka 1987: 479.

\section{Type species}

Maratus amalilis Karsch 1878, by subsequent designation of Bonnet 1957: 2713.

\section{Remarks}

The salticid genus Maratus currently contains six named species (Żabka 1987, 1991; Waldock 1995; Platnick 2008), although 15 new species have been recognised during a review of all Australian museum collections (Waldock, unpublished data).

\section{Maratus limatei new species \\ Figures 1-8}

\section{Material examined}

Holotype

Australia: Western Australia: 3. Two Peoples Bay Nature Reserve, track to Robinsons Gully, $345845^{\prime}$ S 1181110 'E, 14 October 2006, M. I. Moir, I.M. Waldock (WAM T78896). 


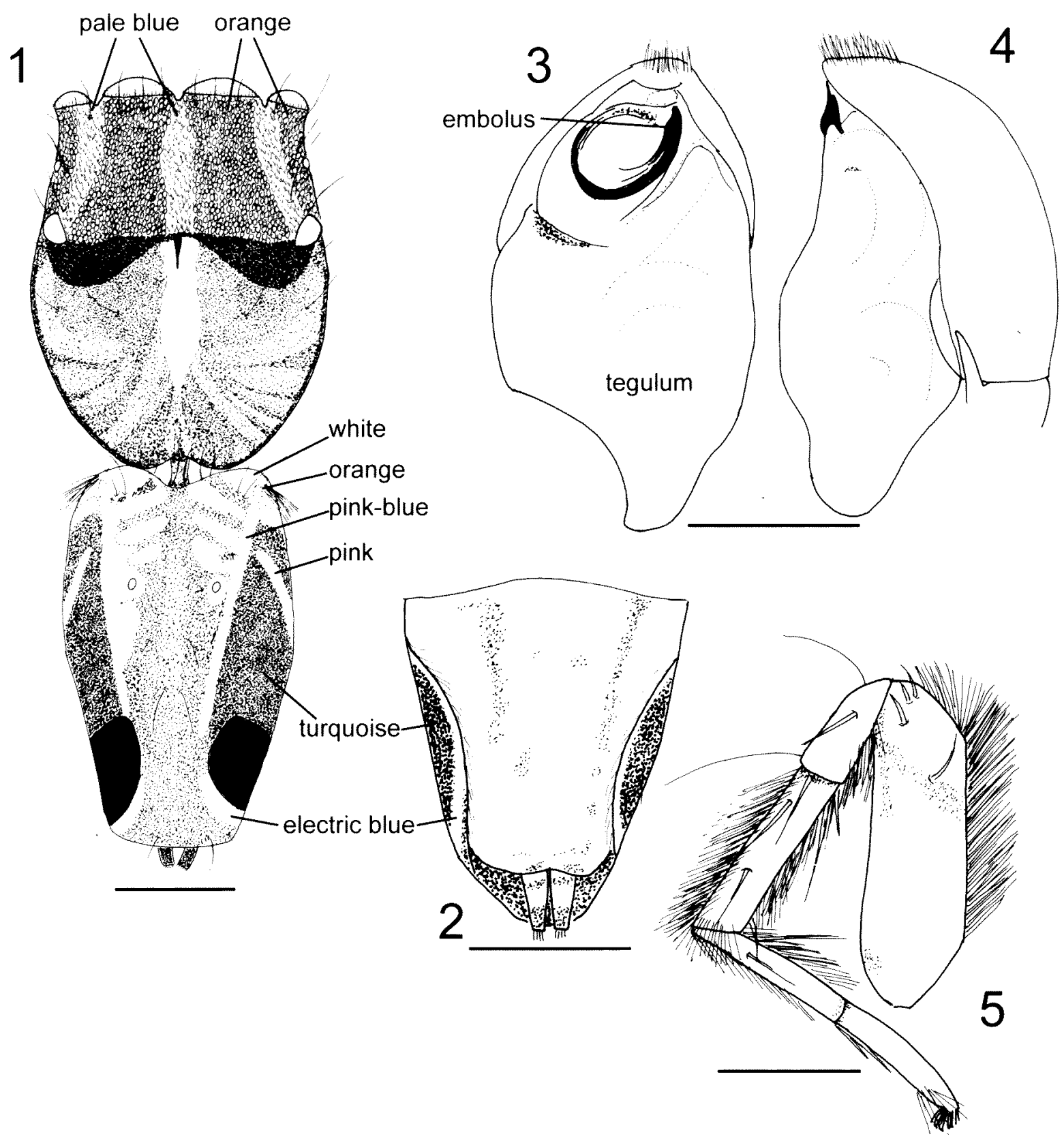

Figures 1-6 Maratus linnaei new species, holotype of (WAM T78896): 1, cephalothorax and abdomen, dorsal; 2 , abdomen, ventral, folded abdominal flaps; 3 , left pedipalp, ventral; 4 , left pedipalp, retrolateral; 5 , right leg III, retrolateral.

\section{Paratypes}

Australia: Western Australia: 10 , Two Peoples Bay Nature Reserve, 345' $58^{\prime \prime} S$ 118 $11^{\prime} 18^{\prime \prime}$, Firebreak Valley bottom, wet pitfall traps, 23-30 October 1995, S. Comer (WAM T75712); 1 \&, Two Peoples Bay Nature Reserve, track to Robinsons Gully, 34 58 45"S 118 11'10"E, 14 October 2006, M.L. Moir, J.M. Waldock (WAM T88431); 1 + , Two Peoples Bay Nature Reserve, track to Robinsons Gully, 34 58'54'S 118 11'11"E, 14 October 2006, M.L. Moir, J.M. Waldock (WAM T78897); 1 o, 1 \&, Two Peoples Bay Nature Reserve, track to Robinsons Gully, 34 $58^{\prime} 45^{\prime \prime} \mathrm{S} 118^{\circ} 11^{\prime} 10^{\prime \prime} \mathrm{E}$, on sandy track, 14 October 2006, M.L. Moir, J.M. Waldock (WAM T79108, 79109).

\section{Diagnosis}

Maratus linnaei differs from all other described and undescribed species currently known by the following combination of characters: male with abdominal lateral edges extended into flaps that fold under the abdomen but do not reach venter; abdomen with brown and tan patches and two iridescent pink to blue-coloured stripes extending on either side diagonally between brown patches; crescent-shaped electric blue patches each side of spinnerets on matte black patch on dorsal abdomen; tibia III with brushes of cream and grey bristles and hairs on all segments; legs I and II with shorter creamcoloured brushes on femora; alternate blue and 

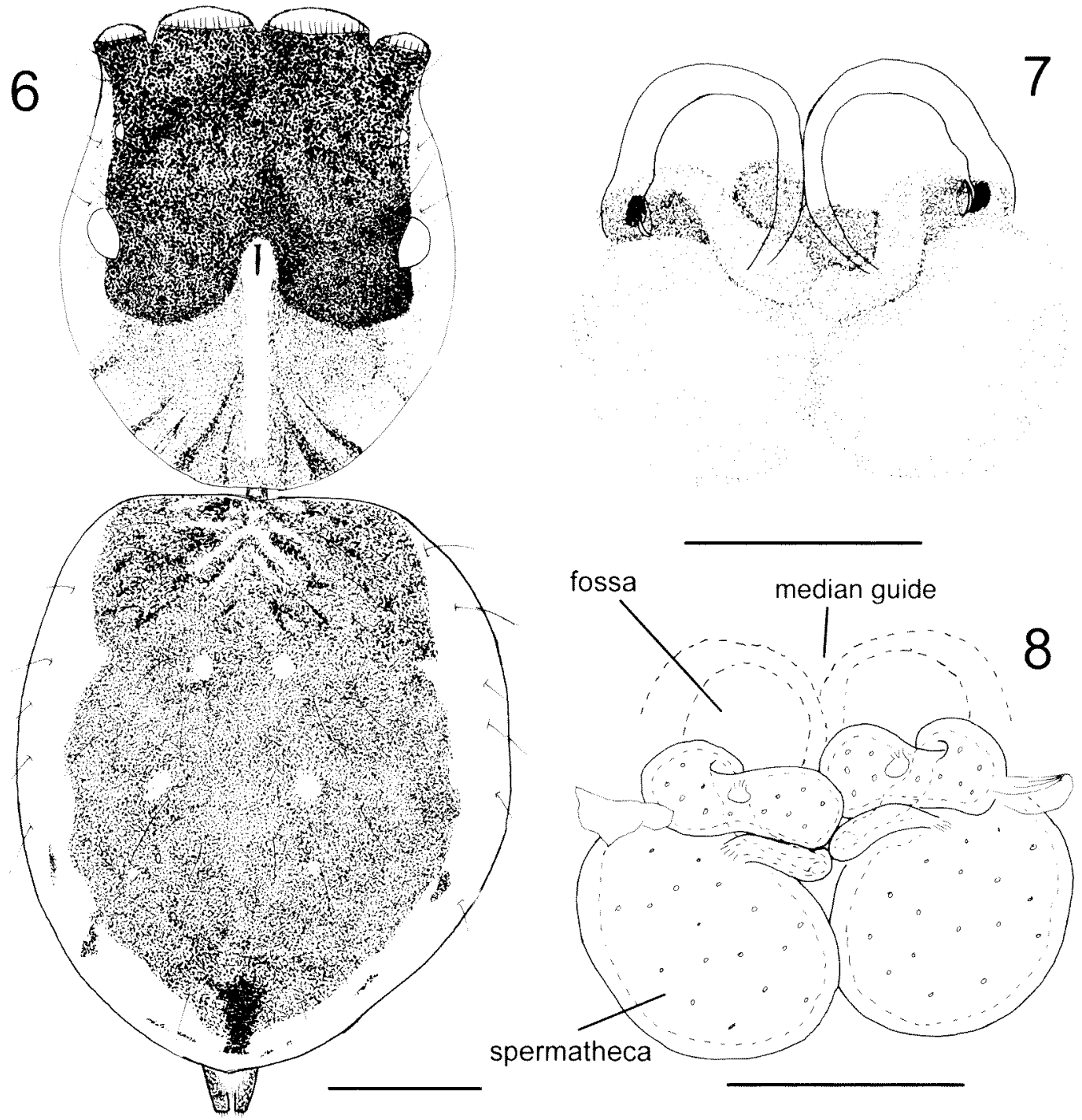

Figures 7-9 Maratus linnaci new species, paraty
epigyne, ventral; 8 , epigyne, dorsal.

orange strips of squamous hairs extending between and behind anterior medium eyes over ocular area. Female with large grey patch over most of abdomen; venter cream-coloured with greyish longitudinal stripes; epigyne with swollen proximal receivers, intermediate canals short and lying lengthwise across anterior portion of spermathecae with openings off-centre of anterior margin of spermathecae.

\section{Description}

\section{Male (holotype)}

Cephalothorax: dark brown without white hairs around lateral edges, border dark grev. Dense scattering of orangey and pale blue squamous hairs covers ocular region as narrow stripes of pale blue from anterior of posterior lateral eyes to gap between anterior lateral eyes and medium eyes and a thinner stripe of pale blue hairs anterior to fovea extending to gap between medium eyes, rest of ocular area filled in with wider stripes of orange hairs. Behind anterior lateral eves and along posterior edge of ocular area are two black areas lacking scattered short white hairs. Extending posteriorly from edge of ocular area a stripe of dense white hairs covers fovea extending as far as descending part of cephalothorax. Two patches of white hairs also extend posteriorly from under posterior lateral eyes. Anterior eyes fringed with bright orange hairs dorsally and white hairs between anterior lateral eyes and medium eyes; rest of cephalothorax lightly covered with scattering of short white hairs. Clypeus dark yellow, chelicerae tan-coloured. Maxillae dark vellow, light cream distally, labium tan. Sternum yellow with grey speckling.

Abtomen: rectangular, dorsal surface covered with a species specific pattern of short squamous hairs of pink, pink-blue diagonal stripes laterally 
and two longitudinal pink-blue stripes meeting with matte-black patches and two electric-blue crescents just anterior to spinnerets. Dorsal abdominal scute developed as lateral flaps which fold along abdomen sides not extending over venter, but can be extended laterally to exhibit a continuation of dorsal pattern. Abdominal pattern consists of tan-coloured central patch bordered by pink-blue longitudinal stripes which extend into larger patches anteriorly and become white with blue flecks. Two narrow diagonal stripes of iridescent pink to pale blue squamous hairs extend to abdomen edges. Sides of abdomen dark brown overlain with dark turquoise-coloured squamous hairs except posterior third which has matte black patches edged with electric blue squamous hairs patches anterior to spinnerets. Small patches of bright orange squamous hairs at anterior corners of abdomen associated with tufts of bristles. Edges of abominal flaps with thin line of electric blue squamous hairs along border, rest of flaps dark brown overlain with dark turquoisecoloured squamous hairs. Stiff black bristles scattered over dorsal abdomen and cephalothorax. Venter of abdomen pale yellow with two grey longitudinal stripes and grey speckling between. Long white hairs border abdominal flaps. Spinnerets dark grey.

Pedipalp: Palp light cream with scattered grey patches (Figures 3, 4). Tibial apolphysis narrow, straight with tip slightly hooked. Ventral surface of palpal tibia without spurs. Cymbium, dorsal tibia and dorsal patella densely covered with long white hairs. a single very long black hair on dorsal palpal patella and tibia as well as a few on external ventral side just under tegulum. Embolus tightly coiled and tucked under tip of cymbium; tegulum with two bulges, one behind the other, next to embolus; anterior bulge slightly smaller.

Legs: femorae, patellae, tibiae, metatarsi and tarsi yellow with greyish bands on all segments except tarsi. Covered with short white hairs interspersed with black bristles, except for leg III which has a brush of bristles and thick hairs on dorsal and ventral surfaces of femora and tibia, and only ventral surface of patella and metatarsus. Tarsi III covered with long white hairs distally that extend over tips of claws. Dorsal brush thickest and of dark grey and cream bristles, ventral brushes cream only. Femora of legs I and II with shorter brushes of cream-coloured hairs dorsally only. Leg formula: III: IV: I=II.

\section{Female (paratype, WAM T88431)}

Cephalothorax: ocular region and areas posterior to posterior lateral eyes dark brown with short black and cream hairs, rest of cephalothorax brown grading to tan along sides with scattered black and cream hairs. Indistinct striping on cephalothorax sides of brown over dark yellow delineated with white hairs. Border of cephalothorax dark grey. Light tan patch over fovea extending from posterior edge of ocular area in a stripe of dense cream-coloured hairs as far as descending part of cephalothoraX. Abdomen oval with grey sigillae, most of dorsum dark grey extending to spinnerets, laterally cream-coloured with black bristles scattered amongst dark hairs and a small patch of white bristles just above spinnerets. Clypeus creamy yellow with white hairs, chelicerae dark yellow with greyish patches. Maxillae, labia and sternum yellow with grey speckling; venter of abdomen cream with greyish patches in longitudinal stripes. Ventral spinnerets cream-coloured, dorsal spinnerets dark grey.

Epigyne: proximal receivers swollen, overlapping across median guide. Intermediate canals lying across spermathecae and opening mid-laterally into spermathecae. Fertilisation ducts situated laterally on spermathecae. Walls of spermathecae thickened.

Legs: yellow with dark grey banding on all segments. Leg formula: III: IV: I: II.

\section{Variation}

One of the male paratypes (WAM T79108) has orange squamous hairs mirroring pattern of pink lateral stripes and bright blue longitudinal stripes.

\section{Dimensions ( $\mathrm{mm}$ )}

Holotype of (WAM T78896): total length (excluding chelicerae) 3.60. Carapace length 1.75. Abdomen length 1.80. Leg I: femur 0.90, patella 0.50 , tibia 0.45 , metatarsus 0.45 , tarsus 0.30 . Leg II: femur 0.85 , patella 0.50 , tibia 0.45 , metatarsus 0.40 , tarsus 0.35. Leg III: femur 1.45, patella 0.65 , tibia 0.80 , metatarsus 0.80 , tarsus 0.40 . Leg IV: femur 1.00 , patella 0.55 , tibia 0.55 , metatarsus 0.75 , tarsus 0.40 .

Paratype $q$ (WAM T88431): total length (excluding chelicerae) 4.35. Carapace length 2.07. Abdomen length 2.15. Leg I: femur 0.95, patella 0.50 , tibia 0.55 , metatarsus 0.45 , tarsus 0.35 . Leg II: femur 0.90 , patella 0.55 , tibia 0.50 , metatarsus 0.45 , tarsus 0.35. Leg III: femur 1.52, patella 0.65 , tibia 0.85 , metatarsus 0.75 , tarsus 0.50 . Leg IV: femur 1.20 , patella 0.60 , tibia 0.75 , metatarsus 0.85 , tarsus 0.50 .

\section{Etymology}

This species is named in honour of Carolus Linneaus, in celebration of the $250^{\text {th }}$ anniversary of publication of the $10^{\text {th }}$ edition of Systema Naturae. 


\section{Remarks}

Maratus limmi has been collected only from Two Peoples Bay Nature Reserve in southwestern Australia, from Banksin dominated heathland. As indicated by the sparse collections, males of $M$. limati are active during the southern hemisphere spring month of October.

\section{ACKNOWLEDGEMENTS}

I am grateful to Sarah Comer (Department of Environment and Conservation, Albany) for providing one of the specimens used in this study, and to Melinda Moir for her assistance during field work. This study was assisted by funding from Department of Conservation and Land Manage-ment (CALM) and the South Coast Regional Initiative Planning Team (SCRIPT) for the project "Short-range endemic invertebrates of the WA South Coast". Also, many thanks to Mark Harvey for valuable comments on a draft of the manuscript.

\section{REFERENCES}

Bonnet, P. (1958). Bibliographia Araneormm. Vol. 2(4) Douladoure: Toulouse.
Karsch, F, (1878). Diagnoses Attoidarum aliquot novarum Norae Hollandiae collectionis Musei zoologici Berolinensis. Mitteilungen de's Mïndener Entomologischen Verein. Minthen 2: 22-32.

Platnick, N.I. (2008). The World Spider Catalog, version 8.0. American Museum of Natural History: New York. http://research.amnh.org/entomology/spiders/ catalog/INTROIhtml

Simon, E. (1901a). Histoire Naturelle des Araignés, vol. 2. Encyclopédie Roret: Paris.

Simon, E. (1901b). Descriptions d'especes nouvelles de la famille des Salticidae (suite). Anmales de la Sociéti Entomologigne de France 70: 66-76.

Waldock, I. M. (1995). A new species of Maratus from southwestern Australia (Araneae: Salticidae). Records of the Western Australian Museum Supplement 52: $165-169$.

Żaba, M. (1987). Salticidae (Araneae) of Oriental, Australian and Pacific Regions, II. Genera Lycidas and Maratus. Annales Zoologici 40: 451-482.

Zabka, M. (1991). Studium taksonomicznozoogeograficzne nad Salticidae (Arachnida: Araneae) Australii. Wyzsza Szkola Rolniczo-Pothgogiozna a Siadlach, Rozprana Naukoun 32: 1-110.

Manuscript receiced 21 Moy 2008; nccepted 25 Angust 2008 . 